\title{
Impact of various concentrations of crude oil on fungal populations of soil
}

\author{
*O. Obire; E. C. Anyanwu \\ Department of Applied and Environmental Biology, Rivers State University of Science and Technology, P.M.B. 5080, Port \\ Harcourt, Nigeria \\ Received 24 April 2008; $\quad$ revised 15 July 2008; accepted 21 October 2008; available online 1 March 2009
}

\begin{abstract}
The effect of various concentrations of crude oil on fungal populations of soil was investigated for a period of 18 weeks using standard methods. Total fungal counts ranged from 26 to $143 \times 10^{2} \mathrm{cfu} / \mathrm{gsoil}$ while counts of petroleum-utilizing fungi ranged from 2 to $102 \times 10^{2} \mathrm{cfu} / \mathrm{g}$ soil. Analysis of variance and randomized complete block design of counts of total fungi and petroleum-utilizers showed high significant difference between the control and the oil treated soils at $\mathrm{p} \leqslant 0.05$ level. Counts of petroleum-utilizers expressed as a percentage of the corresponding total fungal count of the soils ranged from $4.7 \%$ to $58.8 \%$. Species of fourteen fungal genera were isolated from the soils. These include Alternaria, Aspergillus, Candida, Cephalosporium, Cladosporium, Fusarium, Geotrichum, Mucor, Penicillium, Rhizopus, Rhodotolura, Saccharomyces, Torulopsis and Trichoderma. Of these, ten were petroleum-utilizers and were all isolated from the control and $1 \%$ oil treated soils. Only seven genera were isolated from the $5 \%$ oil treated soil out of which five genera were petroleum-utilizers in both the $3 \%$ and $5 \%$ treatment. The decreasing order of occurrence of a variety of fungal genera (fungal diversity) of both total fungi and petroleum-utilizers is $0 \%$ (control) $>0.5 \%>1 \%$ $>3 \%>5 \%$. This order of fungal diversity is a reverse of the decreasing order of fungal counts of these same soils. This showed that higher concentrations of crude oil has adverse effect on fungal diversity while enhancing the population of a fewer fungi.
\end{abstract}

Keywords: Oil-treated soils, fungal diversity, petroleum-utilizers

\section{INTRODUCTION}

Crude oil is a naturally occurring complex mixture of hydrocarbon and non-hydrocarbon compounds which at appropriate concentration, possesses a measurable toxicity towards living systems. The toxicity of crude oil or petroleum products varies widely, depending on their composition, concentration, environmental factors and on the biological state of the organisms at the time of the contamination. Different species and different life stages of organisms have been demonstrated to have different susceptibilities to pollution (Nelson-Smith, 1973). The scale of pollution depends on the quantity of oil and the damage done to the environment (Colwell and Walker, 1977). In heavily polluted areas, there will be an immediate detrimental effect on the life of flora and fauna (Steinhart and Steinhart, 1972). The Niger Delta area is the center of petroleum production and process activities in Nigeria. The Niger Delta is also known as one of the largest wet lands, encompassing over $20,000 \mathrm{~km}^{2}$ in Southern Nigeria (World Bank, 1995). It is also regarded as one 凶*Corresponding Author Email: omokaro515@yahoo.com Tel.: +234 8061692017 of the richest part of Nigeria in terms of natural resources, which include large oil and gas deposits, as well as extensive forests, suitable agricultural land and abundant fish resources. Despite the tremendous natural and human resources base, a report from the World Bank (1995) reported that the region's potential for sustainable development remains unfulfilled and its future is being threatened by diverse environmental problems of which oil pollution is most paramount.

Several studies on spills and environment in the Niger Delta area and other tropical areas throughout the world consistently showed that areas that are directly exposed to large or repeated oil spills or leaks frequently exhibit long-term environmental problems (Amadi et al., 1996; Obire, 1988; 1990). On the terrestrial environment, oil spills cause extensive damages ranging from the destruction of terrestrial flora and fauna to biomagnifications of the toxic components of the petroleum conversion of arable land to barren soils and the destruction of the aesthetic quality of the environment. Other environmental consequences of oil pollution include the adverse effects on the soil 
microflora and ground water contamination. In Nigeria and in the Niger Delta in particular, oil pollution problems of both terrestrial and aquatic environments are very prevalent. Both macro and micro-organisms, as well as plants roots are haboured by the soil. It is one of the most dynamic sites of biological interactions in nature. A report by Alexander (1977) shows that many of the biochemical reactions concerned in the mineralization of soil organic matter and in the nutrition of plants particularly agricultural crops are mediated by micro-organisms whose activity is governed by the soil environment. Fungi are important agents in biogeochemical cycling and mineralization. Any factor therefore whose presence in the environment affects these microbial activities, also adversely affects plant growth, as well as detoxification of organic pollutants. Micro-organisms are useful in predicting the impact of a particular stress on the environment by their ability to respond to these adverse conditions through a change in their numbers (Clark and Patrick, 1987; McKinley et al., 1982; Obire, 1988) and the elimination of some special types. Many of the toxicity experiments have been conducted in abnormally high concentrations of up to $100 \mathrm{ppm}$ where the oil is placed in suspension by various mechanical and chemical means. However, such toxicity determinations are usually made under artificial laboratory conditions which can be accurately controlled and measured. Different investigators have also used different concentrations of crude oil in their toxicity determinations.

The objective of this investigation is to assess the impact of various concentrations on the fungal population of a soil in the Niger Delta prone to crude oil pollution. This is conducted by the enumeration of the fungal population (heterotrophic and hydrocarbon-degrading fungi) and the identification of both heterotrophic and hydrocarbon-degrading fungi (types or diversity) in control and in crude oil polluted soils.

\section{MATERIALS AND METHODS}

Study area and source of crude oil

The study is a fallow patch of land in NkpoluOroworukwo, Mile 3, Diobu area of Port Harcourt, Rivers State that was fenced to prevent animal and human encroachment. The study was conducted between the months of August and December, 1999.
The land was marked out and prepared into unpolluted, crude oil-polluted and bioremediated plots from which soil samples for the study were collected and analyzed. Crude oil (Brass blend) with a specific gravity (API) of 41.7-43.0 and black in colour was obtained from Nigeria Agip Oil Company (NAOC), Obrikom flowstation, Rivers State, in large sterile plastic containers.

\section{Experimental design and treatment levels and application of crude oil}

The experimental design was the randomized complete block design (RCBD). Each plot or block unit was $30 \mathrm{~cm} \times 30 \mathrm{~cm}$. Since microbially influenced agricultural soil fertility is in the range of $0-15 \mathrm{~cm}$ depth, then the volume of bulk soil per plot was $30 \times 30 \times 15=$ $13,500 \mathrm{~cm}^{3}$. The study involved 5 treatments, each replicated three times. Assignment of treatment to plot was carried out using the table of random numbers of Gomez and Gomez (1984). The volume of crude oil applied to individual plots in various concentrations $(0.5 \%$, $1 \%, 3 \%$ and $5 \%$ ) was calculated in millilitres using a $1: 1$ soil/oil volume relationship (Amadi et al., 1993). The appropriate amount of crude oil was measured and applied evenly on the surface of each plot and allowed to sink gradually for 30 min except for the unpolluted plots (0\% crude oil) which served as controls. Since microbiological oxidation of any organic substrate requires that certain specific conditions be met (McGill and Nyborg, 1975), the following subsequent treatments were carried out in order to speed up the rate of crude oil degradation in the soil. All experiment and control plots were tilled once a week in order to make oxygen available to the microorganisms involved in crude oil degradation process. All experiment and control plots were watered before oil application to $60 \%$ of water holding capacity (Margesin and Schinner, 1997) and subsequently as required.

\section{Collection of soil samples for analysis}

Soil samples (400 g) from surface soil (0-15 cm depth) was collected from each plot consecutively after tilling with a sterile scoop and transferred into sterile polythene bags. Soil sample collections were made from 3-4 random points per plot and then mixed to form composite soil samples. Small portions (3 g) of the composite samples were transferred into sterile bottles using sterile spatula for microbiological quality determination. All microbiological analyses were carried out within $24 \mathrm{~h}$ after sample collection. All soil samples for future 
analyses were stored at $4 \pm 2{ }^{\circ} \mathrm{C}$ according to ISO and OECD standards. Soil samples from each plot was collected before pollution, $24 \mathrm{~h}$ after pollution, weekly intervals for three weeks, biweekly intervals for six weeks and finally, triweekly intervals for nine weeks. This lasted for 18 weeks and the sampling intervals were recorded in weeks as $24 \mathrm{~h}, \mathrm{~W}_{1}, \mathrm{~W}_{2}, \mathrm{~W}_{3}, \mathrm{~W}_{5}, \mathrm{~W}_{7}, \mathrm{~W}_{9}$, $\mathrm{W}_{12}, \mathrm{~W}_{15}$ and $\mathrm{W}_{18}$.

\section{Media for isolation of fungi}

The following media were used for isolation and enumeration of fungi. Potato dextrose agar (PDA) was used for isolation and enumeration of total heterotrophic fungi. The composition of the medium was potato, $200 \mathrm{~g}$; distilled water, $500 \mathrm{~mL}$; glucose-D, $15 \mathrm{~g}$ and agar No. 1, 20 g. Tetracycline was added to prevent bacterial growth and permitted selective isolation of yeasts and moulds (Harrigan and McCance, 1990; Paul and Clark, 1988; Walker and Colwell, 1976). The medium was allowed to cool to $45^{\circ} \mathrm{C}$ under aseptic condition, mixed thoroughly and then dispensed into sterile Petri dishes to set. Oil agar medium was prepared according to the mineral salts medium (MSM) composition of Mills et al. (1978) as modified by Okpokwasili and Okorie (1988). The composition of the medium was $\mathrm{NaCl}, 10.0 \mathrm{~g}$; $\mathrm{MgSO}_{4} .7 \mathrm{H}_{2} \mathrm{O}, 0.42$ g; $\mathrm{KCl}, 0.29$ g; $\mathrm{KH}_{2} \mathrm{PO}_{4}, 0.83$ g; $\mathrm{Na}_{2} \mathrm{HPO}_{4}, 1.25$ g; $\mathrm{NaNO}_{3}, 0.42$ g; agar, 20 g; distilled water, $1 \mathrm{~L}$ and $\mathrm{pH}$ of 7.2. The medium was used for isolation, enumeration and preliminary identification of petroleum-utilizing fungi (oil-degraders). The medium was prepared by the addition of $1 \%(\mathrm{v} / \mathrm{v})$ crude oil sterilized with $0.22 \mu \mathrm{m}$ pore size Millipore filter paper Moslein France (Obire, 1988) to sterile MSM, which has been cooled to $45{ }^{\circ} \mathrm{C}$ under aseptic condition. Tetracycline was added to prevent bacterial growth. The MSM and crude oil were then mixed thoroughly and dispensed into sterile Petri dishes to set.

Isolation and enumeration of heterotrophic and oilutilizing fungi in treated soils

Soil heterotrophic fungi were estimated by soil dilution plate count method. Sterile physiological saline, i.e. $0.85 \%$ (w/v) sodium chloride was used as diluent for inoculum preparation. $1.0 \mathrm{~g}$ of homogenized, $2 \mathrm{~mm}$ sieved soil sample was aseptically transferred, using a flame-sterilized steel spatula, into a sterile test tube containing $9.0 \mathrm{~mL}$ of the diluent. This gave $10^{-1}$ dilution. Subsequently, three-fold $\left(10^{3}\right)$ serial solutions were prepared from the $10^{-1}$ dilution. $0.1 \mathrm{~mL}$ aliquot of
$10^{-3}$ dilution of each soil sample was aseptically removed with a sterile pipette and separately spread plated with flame-sterilized glass spreader on well-dried PDA plates and onto oil-agar plates in triplicates. The cultured plates were incubated at room temperature for 5 to 7 days. After incubation, the colonies that developed on the PDA plates were counted and recorded as counts of total viable heterotrophic fungi. For the estimation and preliminary identification of petroleum-utilizing fungi, oil agar plates were inoculated with $0.1 \mathrm{~mL}$ aliquots of $10^{-2}$ dilutions of the soil samples incubated at room temperature for 7 days. Colonies which developed and showed growth of colonies in the oil were counted, computed and recorded as petroleum-utilizing moulds. The colonies counted were expressed as colony forming unit (cfu) per gram soil. The counts of petroleum degraders was further calculated and expressed as a percentage of the total heterotrophic population (of fungi) rather than as total numbers of petroleum degraders per se (Walker and Colwell, 1976). Discrete colonies were subcultured onto fresh medium for the development of pure isolates, which were stored on potato dextrose agar slants for subsequent characterization and identification tests.

Confirmatory identification of true petroleumutilizing fungi and presumptive identification of fungal isolates

Crude oil utilization test was carried out for the confirmatory identification of actual petroleum-utilizing moulds using isolates obtained from the oil agar preliminary isolation medium. The composition and preparation of the crude oil utilization test medium was the same as that of oil agar medium except that oil was made available via vapour phase transfer (Thijsse and van der Linden, 1961).

Putative petroleum-utilizing fungal isolates were streaked on plates of agar medium (one isolate per plate). In the inside of the Petri dish cover was placed a sterile filter paper (Whatman, No. 1) saturated with filter-sterilized crude oil used in the study. This was aimed at supplying hydrocarbons as sole sources of carbon and energy for the growth of the microorganisms on the mineral salts agar medium surface through vapour phase transfer. All the plates were inverted and incubated at $28 \pm 2{ }^{\circ} \mathrm{C}$ for 7-14 days (Okpokwasili and Amanchukwu, 1988). Uninoculated plates served as control. Colonies appeared on the mineral salts agar medium plates were picked and purified on plates of 
potato dextrose agar. Pure isolates were finally transferred onto petroleum dextrose agar slants and were considered as confirmed petroleum-utilizing fungi. For the presumptive identification of fungal isolates, pure fungal cultures were observed while still on plates and after wet mount in lacto-phenol on slides under the compound microscope. Observed characteristics were recorded and compared with the established identification key of Barnett and Hunter (1972) and Malloch (1997).

\section{Statistical analysis}

Statistical analysis was performed using analysis of variance (ANOVA) and the randomized complete block design (RCBD) on the data obtained for the fungal counts. ANOVA was performed on all the treatment, while least significant difference test (LSD) was performed between each treatment and on control with reference to Gomez and Gomez (1984).

\section{RESULTS AND DISCUSSION}

The result of the average counts of total fungi $\left(\times 10^{2} / \mathrm{cfug}\right.$ soil) and the average counts of petroleumutilizing fungi $\left(\times 10^{2} / \mathrm{cfug}\right.$ soil $)$ in the soils treated with various concentrations of crude oil are as shown in Figs. 1 and 2, respectively.

The counts of total fungi at $0 \%$ oil treatment ranged from 35 to 48 with an average count of 41.5 ; 36 to 58 with an average count of 48.6 for $0.5 \%$; 33 to 64 with an average count of 51.9 for $1 \%$; 32 to 85 with an average count of 66.8 for $3 \%$ and 29 to 96 with an average count of 79.7 for $5 \%$ oil treatment. While the counts of petroleum-utilizing fungi in the soils ranged from 2 to 6 with an average of 3.4; 4 to 11 with an average count of 8.3, 7 to 21 with an average count of $16.3,5$ to 50 with an average count of 28.1 and from 5 to 47 with an average count of $28.8 \mathrm{cfu} / \mathrm{g}$, respectively.

The petroleum-utilizing fungal counts expressed as percentage (\%) of the corresponding total fungal counts in the soils are as shown in Fig. 3. Values ranged

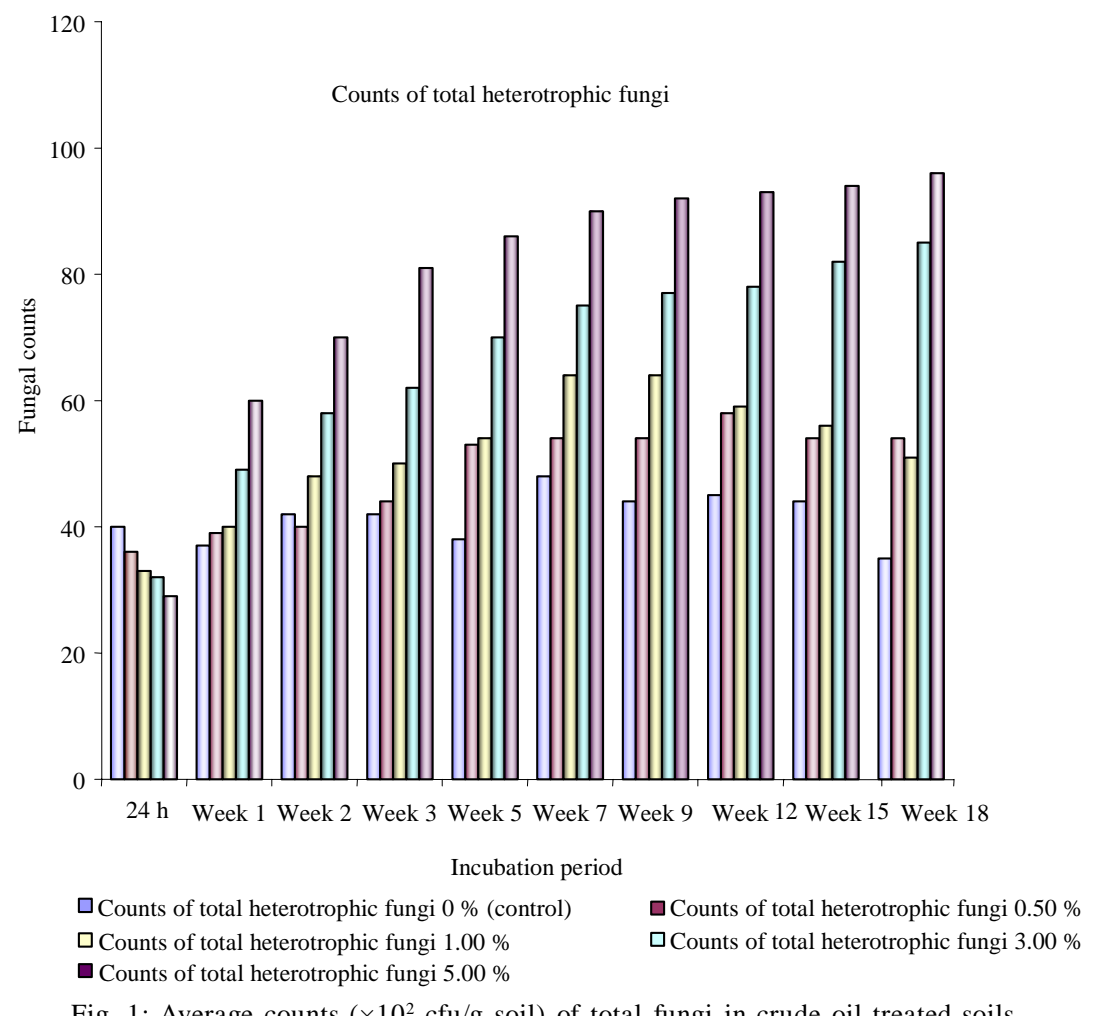




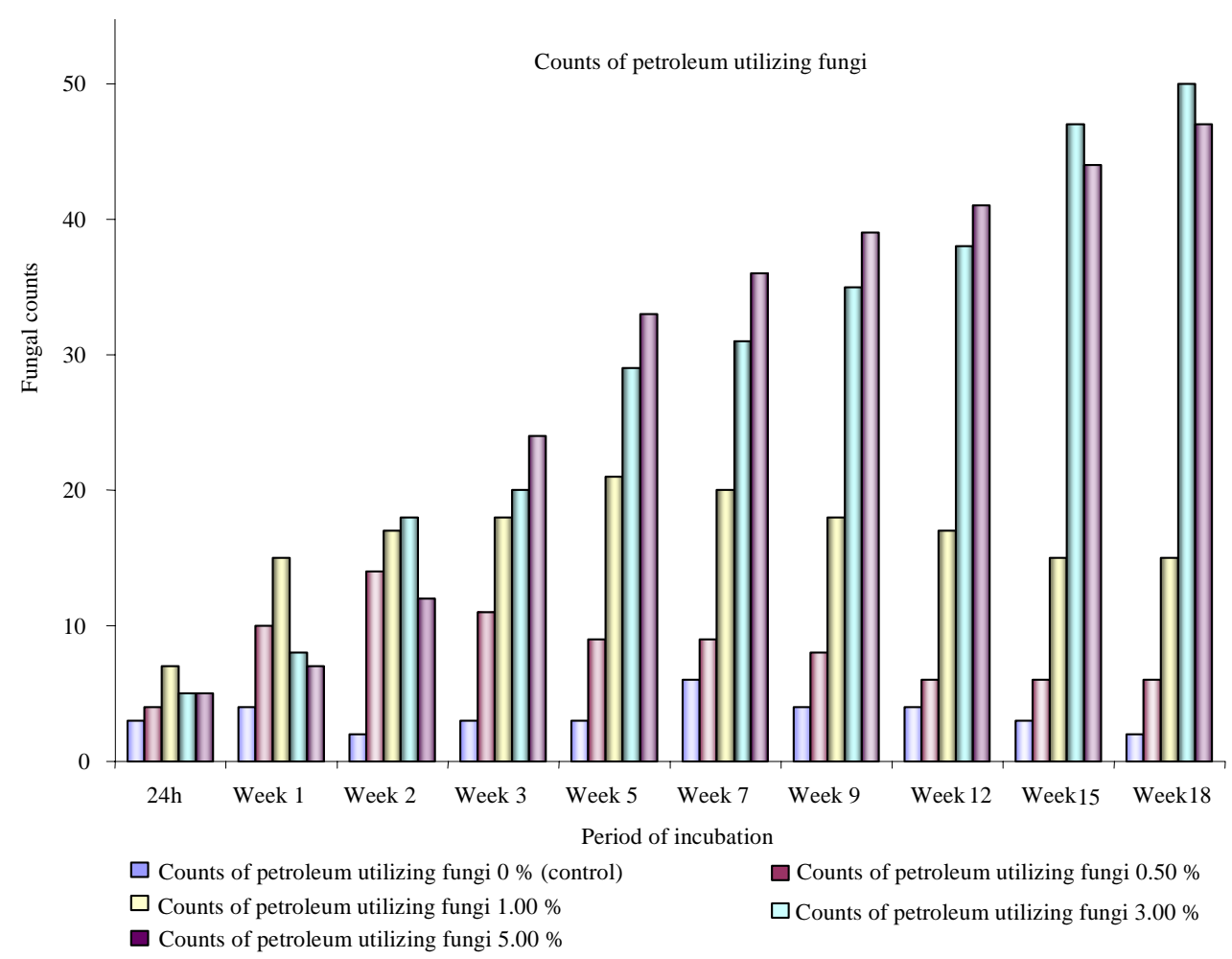

Fig. 2: Average counts $\left(\times 10^{2} \mathrm{cfu} / \mathrm{g}\right.$ soil) of petroleum-utilizing fungi in treated crude oil polluted soils

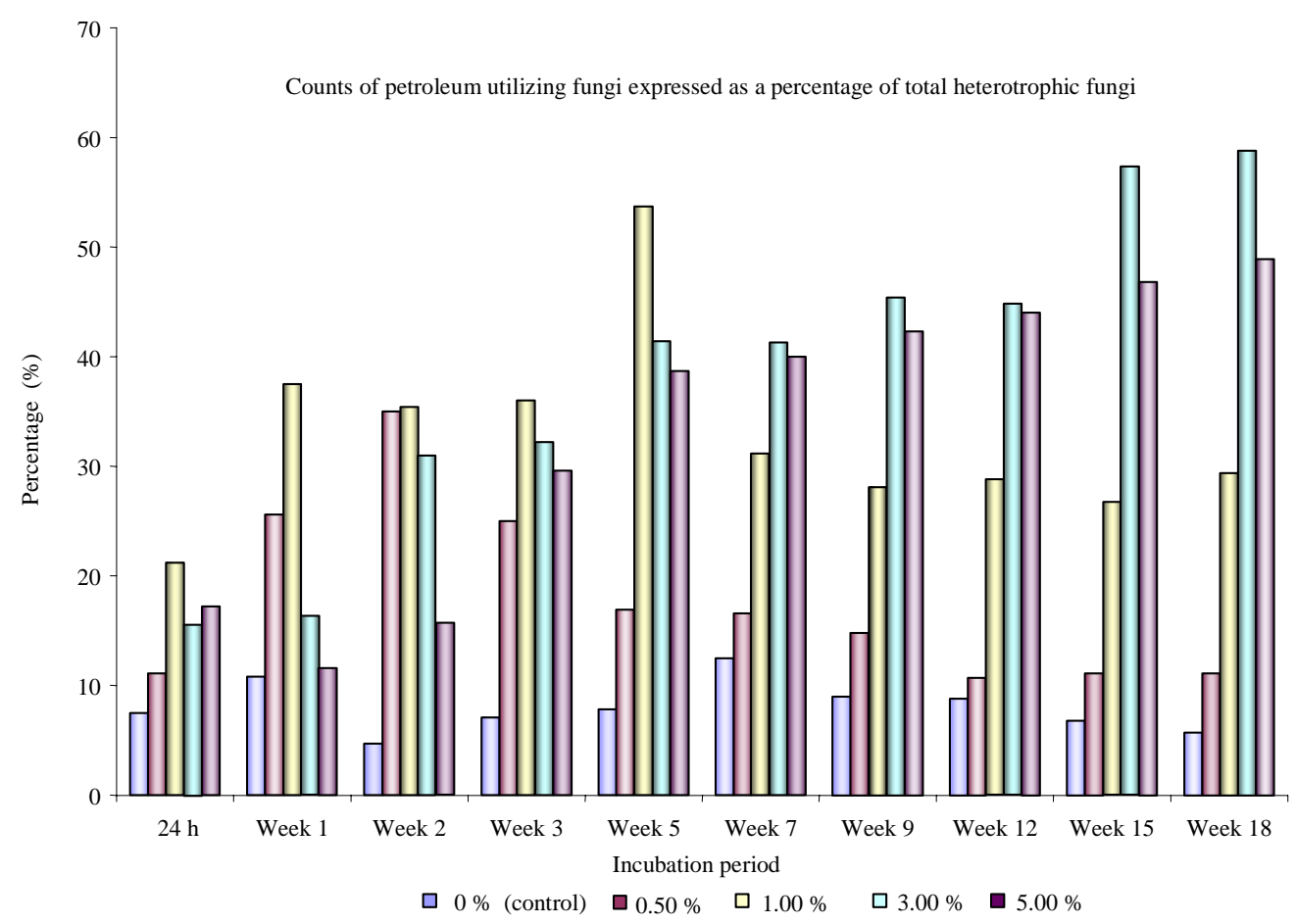

Fig. 3: Counts of petroleum utilizing fungi expressed as a percentage (\%) of total heterotrophic fungi 
from 4.7 to $12.5 \%$ for $0 \%$ oil treatment (control), 10.7 to $35 \%$ for $0.5 \%$ oil treatment, 21.2 to $53.7 \%$ for $1 \%$ oil treatment, 15.6 to $58.8 \%$ for $3 \%$ oil treatment and 11.6 to $48 \%$ for $5 \%$ oil treatment. The statistical analysis of the counts of the total heterotrophic fungi and the counts of petroleum-utilizing fungi in the control and oil-polluted soils showed that there is a high significant difference between the control and the oil treated soils at $p \leqslant 0.05$ level of significance with the average total counts being lowest in the control soil. The computed F-values for the counts of total heterotrophic fungi and the counts of petroleum-utilizing fungi were 33.31 and 11.14 respectively whereas the tabular F-value is 2.63. The order of decreasing average counts of fungi in the soils treated with various concentrations of crude oil is $5 \%>3 \%>1 \%>0.5 \%>0 \%$.

Apart from $24 \mathrm{~h}$ after pollution and week 1 , the counts of total heterotrophic fungi were more in polluted soils than in natural soil, which is the control $(0 \%)$. The order of decreasing average fungal counts of soils after $24 \mathrm{~h}$ of pollution was $0 \%>0.5 \%>1 \%>3 \%>5 \%$. The counts of petroleum-utilizing fungi were generally lowest both in control ( $0 \%$ pollution) and at $24 \mathrm{~h}$ after pollution. At week 1, a general increase was observed especially in $1 \%, 3 \%$ and $5 \%$ and then $0.5 \%$; but in $0 \%$ (control) there was no noticeable increase. This result suggests that the petroleum utilizing fungi were adapted to the quantity of hydrocarbons in the environment hence the increase in the counts of petroleum-utilizing fungi a week after pollution. Obire and Nwaubeta $(2001 ; 2002)$ in a related study on bacteria reported similar findings. The initial reduction in fungi population that always occur before its rise in number again when crude oil is added to the soil is be attributed to oil toxicity. Some microorganisms are killed or inhibited by toxic fractions in the oil, while other heterotrophic organisms degrading the oil are increasing in number. The toxicity of crude oil or petroleum products varies widely, depending on their composition and concentration. The scale of pollution depends on the quantity of oil and the damage done to the environment (Colwell and Walker, 1977). In heavily polluted areas, there will be an immediate detrimental effect on biological forms (Steinhart and Steinhart, 1972).

The total average counts of petroleum-utilizing fungi were generally higher in polluted soils than in natural soil ( $0 \%$ or control). There was a progressive increase in petroleum-utilizing fungi for $0.5 \%$ and $1 \%$ polluted soils to a certain period, after which the petroleumutilizing fungi entered the decline growth phase. The decline growth stage observed in polluted soils towards the end of incubation period may have been as a result of nutrient exhaustion and introduction of toxic metabolites (McGill and Nyborg, 1975). While in the $3 \%$ and $5 \%$ oil polluted soils, the numbers increased throughout the investigating period. This shows that the nutrients provided by the addition of these higher concentrations of crude oil were yet to be exhausted.

The percentage of petroleum-utilizing fungi in $0 \%$ (i.e. control) was the highest at week 12 and decreased at weeks 15 and 18 . For $0.5 \%$, between $24 \mathrm{~h}$ after pollution and weeks 1 to 3 , there was also fluctuation while week 5 had the highest count followed by week 7 ; thereafter, a decrease was observed from week 9 to 18. For $1 \%, 3 \%$ and $5 \%$ level treatments, there were remarkable increases in the counts of the petroleumutilizing fungi. At $1 \%$, its highest count was at week 5 ; for $3 \%$, its highest count was at week 18 and for $5 \%$, its highest count was at week 18 also. The percentage of petroleum-utilizing fungi in natural soil ( $0 \%$ control) fluctuated throughout the investigation period while the percentage of petroleum-utilizing fungi in polluted soil only increased gradually and consistently with the higher counts in weeks 15 and 18. The percentage of petroleum hydrocarbon utilizers in a particular environment appears to be an index of the presence of hydrocarbons in that environment and environmental exposure to petroleum hydrocarbons. These results agree with the reports of Mulkins-Philip and Stewart (1974) and Obire (1988).

During the present investigation, heterotrophic fungal species belonging to a total of fourteen known genera and one unidentified fungus were isolated from the control and oil treated soil samples. These include Alternaria sp.; Aspergillus sp.; Cephalosporium sp.; Cladosporium sp.; Fusarium sp.; Geotrichum sp.; Mucor sp.; Penicillium sp.; Rhizopus sp. and Trichoderma sp. which were moulds and Candida sp.; Rhodotolura sp.; Saccharomyces sp. and Torulopsis sp which were yeasts isolates. Eight of these moulds, viz.; Aspergillus sp.; Cephalosporium sp.; Cladosporium sp.; Fusarium sp.; Geotrichum sp.; Mucor sp.; Penicillium sp. and Trichoderma sp. and two yeast isolates - Candida sp. and Rhodotolura sp were petroleum-utilizers. All these fungi were isolated from the control soil (0\% oil pollution); all except 
Torulopsis sp. and Saccharomyces sp. were isolated from $0.5 \%$ and $1 \%$ oil treated soils, respectively. Species of ten genera which excluded the unidentified species, Alternaria, Rhizopus, Saccharomyces and Torulopsis were isolated from the $3 \%$ oil treated soil, while species of only seven genera, including Aspergillus sp., Cladosporium sp., Fusarium sp., Geotrichum sp., Mucor sp., Penicillium sp. and Candida sp. were isolated from the $5 \%$ oil treated soil. The ten fungal genera which showed the ability to utilize crude oil (petroleum utilizing fungi) were all also isolated from both the control ( $0 \%$ ) and $1 \%$ oil treated soils. Species of seven genera except Cephalosporium sp., Fusarium sp. and Trichoderma sp. were isolated from the $1 \%$ treatment. While species of only five genera which were Aspergillus sp., Cladosporium sp., Mucor sp., Penicillium sp. and Trichoderma sp. and Candida sp. were isolated from both the $3 \%$ and $5 \%$ oil treated soils. The decreasing order of isolation or occurrence of a variety of fungal genera (i.e., fungal diversity) of both heterotrophic fungi and petroleum degrading fungi in the oil treated soils is $0 \%$ (control) $>0.5 \%>1 \%>$ $3 \%>5 \%$. This decreasing order of fungal diversity is a direct opposite or reverse of the decreasing order of fungal counts of these same treated soils. This study showed that there is a large increase in both heterotrophic and hydrocarbon-degrading fungal populations after the introduction of oil into the soil. The addition of oil to the soils resulted in selective increases and decreases in the numbers of fungal populations and various fungal genera enriched in response to addition of various crude oils concentrations. The decrease in species diversity (fungal genera) with increasing concentration of added crude oil is as an indication of environmental stress of petroleum hydrocarbons.

Strand et al. (1971) found that rates of alga photosynthesis and nitrogen fixation decreased. Gordon and Prouse (1973) found inhibition of phytoplankton photosynthesis at high concentrations of petroleum hydrocarbons, but that low levels of oil stimulated photosynthetic activities. Another possible sublethal effect of petroleum hydrocarbon on microorganisms involves the bioconcentration of such pollutants. Mukala et al. (1975) found that the Acinetobacter sp grown on hydrocarbons accumulated hydrocarbons in the cytoplasm. They also reported that yeasts and filamentous fungi also sequestered hydrocarbons in the cytoplasm.
The present investigation has shown that the addition of crude oil concentrations $\geqslant 3 \%$ to soils resulted in the selective increase in fungal populations and a reduction of species diversity by the total elimination of certain species. Since microorganisms play an essential role in biogeochemical cycling, interference with microbial metabolic activities by pollutants in the environment can have far reaching ecological consequences.

\section{REFERENCES}

Alexander, M., (1977). Introduction to soil microbiology. $2^{\text {nd. }}$ Ed., John Wiley and Sons, Inc., New York, 467.

Amadi, A.; Dickson, A. A.; Maate, G. O., (1993). Remediation of oil- polluted soils: 1. Effect of organic and inorganic nutrient supplements on the performance of maize (Zea mays L). Water, Air and Soil Pollut., 66 (1-2), 59-76 (18 pages).

Amadi, A.; Abbey, S. D.; Nma, A., (1996). Chronic effects of oil spill on soil properties and microflora of a rainforest ecosystem in Nigeria. Water, Air, Soil Pollut., 86 (1-4), 111 (11 pages).

Barnett, H. L.; Hunter, B. B., (1972). Illustrated Genera of Fungi Imperfecti. $3^{\text {rd. }}$ Ed., Burgess Publication Co., Minneapolis.

Clark, J. R.; Patrick, J. M. Jr., (1987). Toxicity of sedimentincorporated drilling fluids. Mar. Poll. Bull., 18 (11), 600603 (4 pages).

Colwell, R. R.; Walker, J. D., (1977). Ecological aspects of microbial degradation of pertroleum in the marine environment. Crit. Rev. Microbiol., 5 (4), 423-445 (23 pages).

Gomez, K. A.; Gomez, A. A., (1984). Statistical procedures for

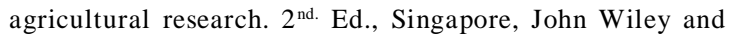
Sons Inc., 680.

Gordon, Jr. D. C.; Prouse, N. J., (1973). The effects of three oils on marine phytoplankton photosynthesis. Mar. Biol., 22 (4), 329-333 (5 pages).

Harrigan, W. F.; McCance, M. E., (1990). Laboratory methods of food and diary microbiology. $8^{\text {th }}$ Ed., Academic Press London, 452.

Malloch, D., (1997). Moulds isolation, cultivation and identification. Department of Botany University of Toronto, Toronto, Canada.

Margesin, R.; Schinner, F., (1997). Efficiency of indigenous and inoculated cold-adapted soil microorganisms for biodegradation of diesel oil in Alpine soil. Appl. Environ. Microbiol., 63 (7), 2660-2664 (5 pages).

McGill, W. B.; Nyborg, M., (1975). Reclamation of wet forest soils subjected to oil spills. Alberta Institute of Pedology, Canada, Publ. No. G-75-1.

McKinley, V. C.; Federle, J. W.; Bestal, J. R., (1982). Effects of petroleum hydrocarbons on plant litter microbiota in an Arctic lake. Appl. Environ. Microbiol., 43 (1), 129-135 (7 pages).

Mills, A. L.; Breuil, C.; Colwell, R. R., (1978). Enumeration of petroleum-degrading marine and estuarine microorganisms 
by the most-probable number. Can. J. Microbiol., 24 (5), 552-557 (6 pages).

Mukala, R. A.; Lockwood, P. J.; Finnerty, W. R., (1975). Comparative analysis of the lipids of Acinetobacter species grown on hexadecane. J. Bacteriol., 12 (1), 250-258 (9 pages).

Mulkins-Phillips, G. J.; Stewart, J. E., (1974). Effects of environmental parameters on bacterial degradation of bunker crude oils and hydrocarbons. Appl. Microbiol., 28 (6), 915922 (8 pages).

Nelson-Smith, A., (1973). Oil pollution and marine ecology. Plenum Press, New York.

Obire, O., (1988). Studies on the biodegradation potentials of some microorganisms isolated from water systems of two petroleum producing areas in Nigeria. Nig. J. Bot., 1, 81-90 (10 pages).

Obire, O., (1990). Bacterial degradation of three different crude oils in Nigeria. Nig. J. Bot., 3, 93-103 (11 pages).

Obire, O.; Nwaubeta, O., (2001). Biodegradation of refined petroleum hydrocarbons in Soil. J. Appl. Sci. Environ. Manag., 5 (1), 43-46 (4 pages).

Obire, O.; Nwaubeta, O., (2002). Effect of refined petroleum hydrocarbons on Soil physicochemical and bacteriological characteristics. J. Appl. Sci. Environ. Manage., 6 (1), 39-44 (6 pages).
Okpokwasili, G. C.; Amanchukwu, S. C., (1988). Petroleum hydrocarbon degradation by Candida species. Environ. Int., 14 (3), 243-247 (5 pages).

Okpokwasili, G. C.; Okorie, B. B., (1988). Biodeterioration potentials of microorganisms isolated from car engine lubricating oil. Tribol. Int., 21 (4), 215-220 (6 pages).

Paul, E. A.; Clark, F. E., (1988). Soil microbiology and biochemistry. Academic Press Inc., New York.

Steinhart, J.; Steinhart, C., (1972). Blowout: A case study of the Santa Barbara oil spill. Hickel, W. J. Duxbury Press, California.

Strand, J. A.; Templeton, W. L.; Lichatowich, J. A; Apts, C. W., (1971). Development of toxicity test procedures for marine phytoplankton, in: Proceedings of joint conference on prevention and control of oil spills. American Petroleum Institute. Washington DC, 279-286.

Thijsee, G. J. E.; Van der Linden, A. C., (1961). Iso-alkane oxidation by a Pseudomonas. Antonie van Leuwenhoek., 27, 171-179 (9 pages).

Walker, J. D.; Colwell, R. R., (1976). Enumeration of petroleumdegrading microorganisms. Appl. Environ. Microbiol., 31 (2), 198-207 (10 pages).

World Bank, (1995). Defining an environmental development strategy for the Niger Delta. West Central Africa Department, World Bank, Washington DC, 150.

\section{AUTHOR (S) BIOSKETCHES}

Obire, O., Ph.D., Senior lecturer and Head of the Department of Applied and Environmental Biology, Rivers State University of Science and Technology, Port Harcourt, Nigeria. E-mail: omokaro515@yahoo.com

Anyanwu, E. C., M.Sc., Department of Applied and Environmental Biology, Rivers State University of Science and Technology, Port Harcourt, Nigeria. E-mail: omokaro515@yahoo.com

\footnotetext{
This article should be referenced as follows:

Obire, O.; Anyanwu, E. C., (2009). Impact of various concentrations of crude oil on fungal populations of soil. Int. J. Environ. Sci. Tech., 6(2), 211-218.
} 